Running head: CORPORATE SOCIAL RESPONSIBILITY IN BOTSWANA AND MALAWI

Final article:

Lindgreen, A., Swaen, A., and Campbell, T. (2010), "Corporate social responsibility practices in developing and transitional economies: Botswana and Malawi", Journal of Business Ethics, Vol. 90, Suppl. 3, pp. 429-440. (ISSN 0167-4544)

For full article, please contact LindgreenA@ cardiff.ac.uk

\title{
CORPORATE SOCIAL RESPONSIBILITY PRACTICES IN DEVELOPING AND TRANSITIONAL COUNTRIES: BOTSWANA AND MALAWI
}

\author{
Adam Lindgreen, Hull University Business School ${ }^{1}$ \\ Timothy T. Campbell, Hull University Business School ${ }^{2}$ \\ Valérie Swaen, Université catholique de Louvain ${ }^{3}$
}

\footnotetext{
${ }^{1}$ For all correspondence: Professor Adam Lindgreen, Department of Marketing and Business Strategy, Hull University Business School, Cottingham Road, Hull HU6 7RX, the UK. Telephone: + 441482463 096. E-mail: a.lindgreen@hull.ac.uk.

${ }^{2}$ Dr. Timothy T. Campbell, Department of Organisational Behaviour and Human Resource Management, Hull University Business School, Cottingham Road, Hull HU6 7RX, the UK. Telephone: + 441482463 114. E-mail: t.campbell@hull.ac.uk.

${ }^{3}$ Dr. Valérie Swaen, IAG-Louvain School of Management, Université catholique de Louvain, Place des Doyens 1, 1348 Louvain-la-Neuve, Belgium. Telephone: + 321047 9156. E-mail: valerie.swaen@ uclouvain.be.
} 


\title{
CORPORATE SOCIAL RESPONSIBILITY PRACTICES IN DEVELOPING AND TRANSITIONAL COUNTRIES: BOTSWANA AND MALAWI
}

\begin{abstract}
This research empirically investigated the CSR practices of 84 Botswana and Malawi organizations. The findings revealed that the extent and type of CSR practices in these countries did not significantly differ from that proposed by a U.S. model of CSR, nor did they significantly differ between Botswana and Malawi. There were, however, differences between the sampled organizations that clustered into a stakeholder perspective and traditional capitalist model groups. In the latter group, the board of directors, owners, and shareholders were important stakeholders that appeared to be restricting extended stakeholder CSR activities in the Malawi and Botswana organizations. The sampled managers recognized the economic benefits of CSR practices and were not at odds with social objectives.
\end{abstract}

KEYWORDS. Corporate social responsibility; practices; stakeholders; U.S.; Botswana; Malawi; performance outcomes; survey.

\section{Introduction}

Formal writings on corporate social responsibility (CSR) predominantly emerged over the last 50 years (Carroll, 1999). The heavy influence of U.S. literature and conceptualizations is widely recognized (Crane and Matten, 2007; Fox, 2004). However, it is contested that literature developed in the U.S. context of what constitutes CSR and how organizations should act responsibly may well be of limited utility in other contexts. In particular, cultural aspects are highlighted as important in determining what is required by, and expected of, organizations when addressing economic, legal, ethical, and discretionary concerns. 
On the African continent the nature of CSR has received little research focus; this is at odds with the general agreement on the role of business in the economic and social development of Africa through CSR initiatives (Bio-Tchané and Christensen, 2006; Eweje, 2006; Prahalad, 2004). An exception is Visser (2006) who utilizes Carroll's (1991) pyramid model of CSR to propose that in Africa the layers of the pyramid (if taken in terms of relative emphasis) need to be reshuffled in such a way that although economic responsibilities still get the most emphasis, philanthropy is now given second highest priority, followed by legal and then ethical responsibilities. This proposition remains speculative and provocative and would benefit from empirical research; but the findings propounded by Visser (2006) lead to the suggestion that as the relative priorities of CSR in Africa are likely to be different from the classic U.S. context, organizations not only must recognize the cultural context in the determination of appropriate CSR priorities and programs, but also question the benefit of striving for universal, standardized approaches and models for CSR.

Whilst our study examines empirically the above proposals, the study further extends the rationale of CSR theory and considers the nature of CSR variability within Africa. Botswana and Malawi display the economic, social, and political differences inherent across the African continent; it is contended that these differences will influence the make-up and relative importance of CSR both within Africa and between Africa and the U.S.

Botswana has transformed itself since independence in 1966 from one of the poorest countries in the world to a middle-income country with an enviable record of economic growth and progressive social policies. However, the country, like Malawi, faces challenges such as dealing with one of the world's highest known rates of HIV/AIDS infection (World Bank, 2007). Our pilot study revealed a noticeable difference in terms of the role of business in the development of Botswana compared with Malawi. Rather than philanthropy, the major theme of the responses from Botswana managers was the importance of the economic role of 
business. Malawi is one of the world's least developed countries and contends with a largely agricultural based economy that is suffering from poor resource management and degradation; a rapidly rising population that puts more pressure on agricultural lands; and alarming HIV/AIDS infection rate. Malawi lacks natural resources and remains heavily dependent on aid from international financial institutions and individual donors (World Bank, 2008). Our pilot study revealed some optimism across the management sample; the theme of philanthropy and importance to their business was very evident.

We structure the remainder of this article as follows: First, we provide a literature review, which we use to develop a theoretical framework. Second, we describe the methodology we use, and third, we present and discuss the results of our survey of 47 organizations in Botswana and 37 organizations in Malawi and their CSR practices. Fourth and finally, we identify our study's contributions and managerial implications, as well as some limitations, and suggest avenues for further research.

\section{Literature Review and Theoretical Framework}

Corporate social responsibility (CSR) means something, but not always the same thing to everybody (Votaw, 1972, p. 25). As a concept, CSR has been particularly strong in the U.S. (Crane and Matten, 2007). However, there is growing evidence that not only does the meaning and practice of CSR vary between (and often within) organizations, so too is this variation evident across nations (Matten and Moon, 2008). Although there is a growing body of literature investigating cross-national CSR variations, few studies have focused on Africa, and those that do predominantly focus on South Africa. The lack of research in this context is incongruous with the general agreement that the private sector remains one of the best-placed institutions to make a significant positive contribution toward improving social, economic, and environmental conditions in Africa (Visser, 2006). 
The U.S. model of CSR, and particularly the role of philanthropy in the long-term development of Africa, has been questioned. Philanthropic activity has been described as at best uncertain aid, vulnerable to people's sympathies and economic circumstances, which is liable to fluctuations and constant reduction (Levy, 2002). Indeed, the CSR agenda has an ambiguous relationship with international development. It is regarded by some as a vehicle through which the private sector can contribute to poverty reduction and other social objectives, which will not be achieved by governments acting alone. But the agenda also has attracted criticism for being insensitive to local priorities and potentially harming prospects for sustainable livelihoods (Fox, 2004, p. 29).

\section{The meaning and practice of CSR}

Many CSR conceptualizations exist, yet none are universally accepted (Garriga and Melé, 2004). It is claimed that the meaning of CSR is nationally contingent, essentially contested, and dynamic (Matten and Moon, 2008). For the purposes of this article, seeking a detailed universal delineation of CSR is unnecessary as investigating national practices to better understand the concept is the primary aim. However, as a foundation, Carroll (1979) provides an often cited definition of CSR, based on U.S. literature; later, the model was reformulated as a pyramid of CSR where, from bottom to top, economic, legal, ethical, and philanthropic (discretionary) responsibilities lay (Carroll, 1999). The pyramid is probably the most established and accepted model of CSR (Crane and Matten, 2007). Various empirical studies have provided support, particularly in the U.S. context (Aupperle, Carroll, and Hatfield 1985; Burton, Farh, and Hegarty, 2000; Pinkston and Carroll, 1996; Smith, Wokutch, Harrington, and Dennis 2001). Later, Carroll (2004, p. 118) again presented the same pyramid framework, but this time as a pyramid of global CSR and performance. 
However, a criticism of this model, and indeed with much of the CSR literature, is that it is strongly biased toward the U.S. context and the applicability may be limited globally. Whilst all levels of the model play a role in Europe, they clearly have different significance, and are interlinked in a somewhat different manner (Crane and Matten, 2007). For example, ethical responsibilities are claimed to be a higher priority in Europe than in the U.S. Burton, Farh, and Hegarty (2000) found differences in the relative importance of the types of CSR responsibilities between Hong Kong and United States students; Chapple and Moon (2005) demonstrated CSR varied considerably among seven Asian countries; and Kusku and Zarkada-Fraser (2004) found significant variations in corporate citizenship practices among Australian and Turkish organizations. The results of global cross-national studies do largely confirm the categories of CSR propounded by Carroll, but argue that their significance varies.

\section{CSR practice in Africa}

These observations lead to the notion that the meaning and practice of CSR in Africa may differ from the traditional U.S. model (Visser, 2006, p. 195). Visser (2006) recognizes that no comparative empirical study has been conducted, but speculatively argues that economic responsibilities still get the most emphasis as, given the continent's generally high unemployment, debt, and poverty, economic contributions are 'highly prized'. However, philanthropy is given second highest priority for three reasons. First, the socio-economic needs of the African societies in which organizations operate are so great that philanthropy is an expected norm - it is considered the right thing to do by business and the most direct way to improve the prospects of the communities in which business operates. Second, many African societies have become reliant on foreign aid. Third, Africa is generally still at an early stage of maturity in CSR, rather than the more embedded approaches now common in developed countries. Legal priorities are the next level in the African CSR pyramid. It is 
claimed that in Africa there is far less of a pressure for good conduct dictated by the law than in developed countries because of reasons such as a poorly developed legal infrastructure. Finally, drawing on global statistics on corruption in Africa, Visser (2006) suggests that, in practice, ethics remains the lowest CSR priority.

A limited number of empirical studies into the practice of CSR in southern Africa provide some support for Visser's (2006) assertions and those of previous global studies that suggest cross-national variations. A Nigerian study exploring the meaning and practice of CSR for indigenous organizations equated the meaning of CSR with corporate philanthropy and the practice of CSR emphasizing philanthropic responsibilities over and above economic, ethical, and legal responsibilities (Amaeshi, Adi, Ogbechie, and Amao, 2006) the reason being that the meaning and practice of CSR among indigenous Nigerian organizations was mainly shaped by the socio-economic conditions (poverty alleviation, healthcare provision, infrastructure development, education) in which the organizations operate and informed by socio-cultural influences (communalism, ethnic religious beliefs, and charity).

Another Nigerian survey of approximately 5,000 people aimed to determine what the stakeholder values were for people who seek support socially from the corporate world. The results revealed that a focus on the immediate operating environment was considered fundamental to 'good' CSR practice. Education, health, poverty alleviation, and economic empowerment were considered the most important social issues, which Phillips (2006, p. 24) writes, "is a marked contrast to what is considered a corporate obligation in a developedcountry context". Whilst recognizing that Nigerian organizations are beginning to pay more attention to these issues, social needs and CSR practices were often not aligned. Many Nigerian organizations focused on activities that made them 'look good' to their customers rather than paying attention to the social issues deemed most important. 


\section{The research context}

Malawi remains one of the poorest countries in the world, with an average income per capita of around US\$160. Analysts regard this as disappointing given the relative political stability in comparison to other sub-Saharan countries. The economy faces serious problems related to widespread poverty, corruption, and under-development. Agriculture accounts for more than $80 \%$ of export earnings and supports $85 \%$ of the population, but is very vulnerable to weather shocks. Malawi is heavily dependent on donors, who contribute about $40 \%$ to Malawi's annual budget. In 2006, US $\$ 2.3 \mathrm{~b}$ of external debt was cancelled under the Heavily Indebted Poor Country initiative, but there are fears the country may revert to wasteful spending, with little money being spent on poverty reduction (Oxford Economic Country Briefing, 2008; World Bank, 2008). The HIV/AIDS infection rate is around 17\% of the population aged 1549, yet governmental investment in health is low (WHO, 2006; World Bank, 2008).

In contrast, Botswana is considered an African success story. An average income per capita of around US\$5,900 is higher than its near-neighbor South Africa, often regarded as the southern African economic superpower (World Bank, 2008). With only 1.8m people and the world's largest output of diamonds, Botswana has been a model of stability, avoiding the violence, corruption, and boom-and-bust cycles that have plagued many mineral-rich countries. However, the country does have its problems such as the government driving the economy, rather than the "feeble" private sector (The Economist, 2008). HIV/AIDS remains a significant problem. Life expectancy at birth has fallen from 65 in the early 1990s to below 40 years. Yet, Botswana has received praise for its determination in fighting the disease; $86 \%$ of AIDS patients get anti-retroviral treatment and, by 2010, $2.5 \%$ of GDP is earmarked to target HIV/AIDS (The Economist, 2008; Oxford Economic Country Briefing, 2008).

No comparative studies have been published in core CSR journals in these countries; however, the literature review suggests that CSR practice may be influenced by factors such 
as culture, stage of CSR maturity, and the immediate socioeconomic environment. It is therefore proposed that there will be a variation of CSR practice between these countries and the U.S. model as depicted by Carroll's (1999) pyramid. Further, for the same reasons, we suggest that CSR practices will vary between Malawi and Botswana.

\section{Research questions}

The article will discuss the following questions: (a) What are the current CSR practices in Malawi and Botswana organizations? (b) What relative emphasis do different organizations place on different aspects of CSR? (c) How do different stakeholders influence organizations' CSR practices? (d) How do different CSR practices relate to different performance outcome? (e) How do CSR practices compare and contrast between Botswana, Malawi, and the U.S.?

\section{Methodology: Survey Instrument and Data Collection}

Following a pilot study undertaken with 10 managers in Malawi and 10 managers in Botswana, a sample population of 37 managers in Malawi and 47 managers in Botswana participated in the main data collection phase. Our survey questionnaire adapts that of Lindgreen, Swaen, and Johnston (2008); for an in-depth description of the questionnaire we refer to that study.

We collected data through distributing surveys to the participants on a U.K. management masters program being conducted at premises in Gaborone (Botswana) and Lilongwe (Malawi) in July 2008.

\section{Results and Discussion}

\section{Respondent demographics}


The age of the respondents averages 37 years. On average, the respondents have spent 3.8 years in their current position. $52.4 \%$ of respondent's described their job position as not being marketing or CSR related, whilst $38.1 \%$ did describe their position as marketing or CSR related and the remainder $(9.5 \%)$ did not answer.

\section{Organization demographics and nonresponse bias}

The sample represents a variety of organizations (the demographics broadly compare with the general business profile of Botswana and Malawi), with $11.9 \%$ in business-to-business and $27.4 \%$ in business-to-consumer organizations. The products that the organizations offer are distributed as follows: physical goods (6.0\%) and services (33.3\%). However, it must be noted that a significant number of respondents $(60.7 \%)$ did not provide this information.

In terms of duration, $26.2 \%$ of the organizations were established less than 10 years ago; $25 \%$ between 11 and 30 years ago and $31 \%$ more than 31 years ago. The number of employees ranges from less than $20(9.5 \%)$ to 1,000 or more $(11.9 \%)$, with $39.3 \%$ employing between 20 and 99 persons and the remaining 33.3\% employing between 100 and 999 persons.

$62.1 \%$ of the organizations generate $10 \%$ or less of their sales revenue through sales to export markets and $24.9 \%$ more than $10 \%$, the remaining does not know. The 2004 sales revenues of $47.9 \%$ of the organizations were $\$ 10$ million or less. Finally, $23.8 \%$ of the organizations represent a strategic business unit within a larger organization, whereas the remaining organizations constitute a division $(10.7 \%)$, plant $(2.4 \%)$, or subsidiary $(15.5 \%)$ of a larger organization.

\section{CSR practices and relationships to stakeholders}


Using factorial analysis with Varimax rotation, we identify six reliable dimensions of CSR practices that relate to customers (two items, explained variance $=6.311 \% ; \alpha=0.809$ ), suppliers (three items, explained variance $=8.956 \% ; \alpha=0.760$ ), employees (four items, explained variance $=12.205 \% ; \alpha=0.826$ ), financial investors (three items, explained variance $=11.169 \% ; \alpha=0.889$ ), philanthropy (five items, explained variance $=13.255 \% ; \alpha=$ 0.895), and the environment (six items, explained variance $=19.401 \% ; \alpha=0.931$ ). Four items have been deleted for further analyses because they were not well represented in this factorial structure.

On a seven-point scale, respondents indicate that their organizations have adopted specific CSR practices relating to employees $($ mean $=4.69)$, customers $($ mean $=5.34)$, suppliers $($ mean $=4.84)$, and financial investors $($ mean $=5.64)$. To a lesser extent, they also apply CSR practices related to philanthropy $($ mean $=4.10)$ and the environment $($ mean $=4.07)$.

CSR practices are perceived as having a certain impact on all the investigated variables but the lowest influence of CSR is perceived on the morale of employees (mean $=3.18$ on a 5-point scale) and the highest influence on image (mean $=3.65$ on a 5-point scale).

\section{Insert Table 1 about here}

Again using factorial analysis with Varimax rotation, we next distinguish five groups of stakeholders: owners (financial shareholders), CEOs, and boards of directors (three items, explained variance $=17.513 \% ; \alpha=0.863$ ); internal stakeholders, such as employees and middle-level managers (two items, explained variance $=14.278 \% ; \alpha=0.917$ ); market stakeholders, including trade unions, retailers, suppliers, competitors, and customers (five items, explained variance $=16.021 \% ; \alpha=0.793$ ); regulators (two items, explained variance $=$ $14.864 \% ; \alpha=0.702$ ) and other external stakeholders such as local communities and the media (two items, explained variance $=12.466 \% ; \alpha=0.637$ ). Surprisingly, customers were not well represented in this factorial structure. 
Respondents perceive the influence of owners, CEOs, boards of directors as higher in comparison to other sources of influences (mean $=4.01$ on a 5-point scale). Then, in a second round, regulators (mean $=3.47$ on a 5 -point scale) and internal stakeholders $($ mean $=3.27$ on a 5-point scale) have a certain influence, whereas that from market-stakeholders ( mean $=2.54$ on a 5-point scale) and from other external stakeholders (mean $=2.83$ on a 5 -point scale) is lower.

Insert Table 2 about here

\section{Cluster analysis}

To determine the possibility of identifying meaningful groups of organizations in terms of their CSR practices, we perform a cluster analysis on the construct scores. Prior to doing so, we confirm that the different variables used for clustering do not suffer from substantial collinearity, which would bias the analysis (i.e., collinear variables implicitly get weighted more heavily; Hair et al., 1998). All variance inflation factors are below 3.0, which is significantly less than the recommended cut-off value of 10 (Hair et al., 1998) and indicates the absence of collinearity. Therefore, we row-center the data, as recommended by Hair et al. (1998), to remove response-style effects (e.g. yea-sayers). To gain the benefits of both hierarchical and nonhierarchical clustering methods, we used both methods sequentially (Hair et al., 1998). Specifically, we use Ward's hierarchical method to establish the most meaningful number of clusters (based on the increase in the average within-cluster distance criterion and the profile of the cluster centers identified), identify potential outliers, and minimize within-group variation. Because we found no outliers, we proceeded with all observations. On the basis of hierarchical cluster analysis we applied a two- cluster solution (not shown here). 
Next, we cluster the organizations using K-means clustering (a nonhierarchical method), with the cluster centers identified in the hierarchical clustering as initial seed points. This second clustering fine-tunes our results, because nonhierarchical methods are less susceptible to outliers, the type of distance measure used, and the inclusion of irrelevant or inappropriate variables (Hair et al., 1998).

The results from the K-means clustering closely mirror the previous organizational profiles. The analysis reveals two different organizational clusters. The first cluster of organizations focus their CSR practices on customers, the environment, and to a lesser extent on suppliers, employees, investors, and philanthropy. The second cluster focused primarily on customers and investors, but also on suppliers and employees. The second cluster may be considered to refer to a traditional model of managerial capitalism, in which the organization pertains only to suppliers, employees, and financial investors that provide basic resources that the organization employs to offer goods and services to customers. The shareholders are the owners of the organizations whose interests the organization should be run on behalf of (Crane and Matten, 2007). In contrast, the first cluster may be considered as a stakeholder view of the organization as it extends the stakeholder groups to include the general public as being affected by the organization's activities. Malawian organizations are almost equally represented in both clusters (14 in cluster one and 15 in cluster two). Organizations from Botswana include 19 in cluster one and 26 in cluster two.

Insert Table 3 about here

\section{Differences across clusters}

\section{Organizational demographics}

No significant difference is found across the clusters in terms of the organizations age. Consequently, there is no evidence that organizations adopt a more traditional capitalistic 
model or a stakeholder orientation dependent on when they were founded. However, the cluster of organizations identified as having a stakeholder perspective are more likely to have a CSR department and/or employees who regularly allocate time to these issues.

Insert Table 4 about here

\section{Perceived influence of stakeholders}

The perceived influence of different stakeholders on CSR practices varied across the two clusters. The board of directors and owners/shareholders were deemed as being more influential in cluster two the implication being that the board of directors and owners/shareholders appear to be acting against an extended stakeholder perspective of socially responsible practices. This result is in contrast to the U.S.A. where investors and the board of directors were found to be influential in extending social and environmental practices (Lindgreen et al., 2008). In cluster one, of the internal stakeholders, the middle managers were demonstrated as being significantly influential in comparison to cluster two. The driver for a wider view of responsible practices appears to be emanating from the middle, rather than the top, of the African respondents' organizations. Local communities, trade unions, and retailers were the remaining stakeholders that differed in their influence on organizational CSR practices, all being deemed as being more influential in the first cluster.

\section{Managers' perceptions of the influence of CSR on performance}

There are a number of significant differences between the two clusters in terms of how CSR practices are perceived to influence organizational performance. Organizations from cluster one-those most involved with CSR - were more convinced about the benefits of CSR activities. These organizations perceived CSR to more positively impact image, financial performance, national/international visibility, and support from the Government. Perhaps 
cluster two is less involved in CSR because they are not convinced of the benefits, or perhaps they do not see the value of CSR because they have not become more involved.

\section{Organizational performance}

To test whether organizations with similar performance levels appear in the same cluster with respect to their CSR practices, respondents answered questions about objective measures of organizational performance, not just subjective measures of CSR's perceived impact on different performance elements. Because $48.8 \%$ of respondents either did not provide sales revenue information or did not know, there was insufficient data to conduct an ANOVA and post hoc contrast analysis. Yet additional information regarding performance relative to expectations was gathered and significant differences were found between the clusters. The organizations with the stakeholder orientation perform better in terms of environmental relations and contributing to the social and economic health of the local community.

Insert Table 5 about here

\section{Conclusions}

Organizations in both Botswana and Malawi significantly engage with socially responsible practices. There are no clear differences between the types of CSR activities in Malawi and Botswana and that proposed by the U.S. literature (Carroll, 1999). Both countries had a relatively positive perception of CSR practices as improving economic performance, rated their ethical policies and practices highly, and there was no clear predilection for philanthropy as had been suggested (Amaeshi et al, 2006; Visser, 2006).

It had been proposed in the literature review that Malawi may be more prone to philanthropic activities given the country's socioeconomic conditions. However, there was no evidence of this as Malawian organizations were almost equally represented in the first 
cluster (stakeholder view of the organization) and the second cluster (traditional model of managerial capitalism). Botswana organizations did not significantly differ from their Malawian counterparts in terms of CSR activities. Therefore, there is no evidence of cultural, socioeconomic or stage of CSR maturity influences on the extent or types of CSR activities that have been adopted by Malawi and Botswana respondents organizations.

However, differences were identified between groups of the sampled organizations. The stakeholder cluster of organizations are more likely to have CSR embedded with a CSR department or employees who have time dedicated to dealing with these issues. The perceived influence of different stakeholders on CSR practices also varied across the two clusters. The more traditional capitalist cluster considered the board of directors, owners and shareholders to be the most influential in dictating social, environmental, and ethical policies and practices. The implication being that these groups are inhibiting an extended stakeholder CSR orientation. Our findings suggest a possible reason for the reluctance of key decision makers to engage with wider CSR activities such as philanthropy and positive environmental practices. Although all managers had a relatively positive perception of CSR practices as improving business performance, those organizations that invest more in CSR activities (cluster two) are more likely to perceive positive benefits associated with CSR. Consequently, the reticence of the cluster two directors, owners and shareholders may be due to not being convinced of the benefits of CSR activities in the African context.

\section{Limitations and future research directions}

Invariably for research that is rare in this context, there are limitations that must be considered. First, we rely on single respondents from organizations and do not include any informants from the organizations' stakeholder groups. Further research should employ a multi-informant research design. Second, our analysis reports on managerial evaluations, not 
actual corporate behaviors. Additional research should include objective indicators of CSR practices, such as the amount of philanthropic donations or an analysis of layoff practices.

Despite these limitations, we believe our study offers several important contributions. First, we add to the currently limited literature of CSR practices in Africa. Second, we do not find evidence of cross-cultural differences in CSR practices either between Botswana and Malawi organizations, or between Botswana, Malawi, and U.S. organizations. Third, we do find that CSR is practiced differently by organizations in our sample with one group adhering to a more traditional capitalistic model and the other a stakeholder perspective. Fourth, the board of directors, owners, and shareholders appeared to be restricting extended stakeholder CSR activities in the Malawi and Botswana organizations. Finally, all managers recognized the economic benefits of CSR practices and were not at odds with social objectives.

\section{References}

Amaeshi, K., Adi, B., Ogbechie, C., and Amao, O.: 2006, 'Corporate Social Responsibility in Nigeria: Western Mimicry or Indigenous Influences?' Journal of Corporate Citizenship 24, 83-99

Aupperle, K., Carroll, A., and Hatfield, J.: 1985, 'An Empirical Examination of the Relationship Between Corporate Social Responsibility and Profitability', Academy of Management Journal 28(2), 446-463.

Bio-Tchané, A. and Christensen, B.: 2006, 'Right Time for Africa', Finance \& Development 43(4), 8-13.

Burton, B., Farh, J.-L., and Hegarty, W.: 2000, 'A Cross-Cultural Comparison of Corporate Social Responsibility Orientation: Hong Kong vs. United States Students', Teaching Business Ethics 4(2), 151-167. 
Carroll, A.: 1979, 'A Three-Dimensional Conceptual Model of Corporate Performance', Academy of Management Review 4(4), 497-505.

Carroll, A.: 1991, 'The Pyramid of Corporate Social Responsibility: Toward the Moral Management of Organizational Stakeholders', Business Horizons 34(4), 39-48.

Carroll, A.: 1999, 'Corporate social responsibility: Evolution of a Definitional Construct', Business and Society 38(3), 268-295.

Carroll, A.: 2004, 'Managing Ethically With Global Stakeholders: A Present and Future Challenge', Academy of Management Executive 18(2), 114-120

Chapple, W. and Moon, J.: 2005, 'Corporate Social Responsibility (CSR) in Asia: A SevenCountry Study of CSR', Business and Society 44(4), 415-441.

Crane, A and Matten, D.: 2007, Business Ethics, 2nd ed. (Oxford University Press, Oxford). The Economist: 2008, 'International: The Southern Star; Botswana', 386(8573), 72.

Eweje, G.: 2006, 'The Role of MNEs in Community Development Initiatives in Developing Countries: Corporate Social Responsibility at Work in Nigeria and South Africa', Business and Society 45(2), 93-129.

Fox, T.: 2004, 'Corporate Social Responsibility and Development: In Quest of an Agenda', Development 47(3), 29-36.

Garriga, E. and Melé, D.: 2004, 'Corporate Social Responsibility Theories: Mapping the Territory', Journal of Business Ethics 53(1/2), 51-71.

Kusku, F. and Zarkada-Fraser, A.: 2004, 'An Empirical Investigation of Corporate Citizenship in Australia and Turkey', British Journal of Management 15, 57-72.

Levy, N.: 2002, 'Against Philanthropy, Individual and Corporate', Business \& Professional Ethics Journal 21, 95-108. 
Lindgreen, A., Swaen, V., and Johnston, W.J.: 2007, 'Corporate Social Responsibility: An Empirical Investigation of U.S. Organizations', Journal of Business Ethics 85(Supplement No. 2), 303-323.

Matten, D. and Moon, J.: 2008, 'Implicit' and 'Explicit' CSR: A Conceptual Framework for a Comparative Understanding of Corporate Social Responsibility', Academy of Management Review 33(2), 404-424.

Oxford Economic Briefing: 2008, Oxford Economic Country Briefings: Malawi and Botswana (Oxford Economics, Oxford).

Phillips, F.: 2006, 'Corporate Social Responsibility in an African Context', Journal of Corporate Citizenship' 24, 23-27

Pinkston, T. and Carroll, A.: 1996, 'A Retrospective Examination of CSR Orientations: Have They Changed?' Journal of Business Ethics 15(2), 199-206.

Prahalad, C. K.: 2004, The Fortune at the Bottom of the Pyramid (FT Prentice Hall, London).

Smith, W., Wokutch, R., Harrington, K., and Dennis, B.: 2001, 'An Examination of the Influence of Diversity and Stakeholder Role on Corporate Social Orientation', Business and Society 40(3), 266-294.

Visser, W.: 2006, 'Revisiting Carroll's CSR Pyramid: An African Perspective', in Pedersen, E.R. and Huniche, M. (Eds.), Corporate Citizenship in Developing Countries (Copenhagen Business School Press, Copenhagen).

Votaw, D.: 1972, 'Genius Became Rare: A Comment on the Doctrine of Social Responsibility Pt 1', California Management Review 15(2), 25-31.

World Bank: 2008, Malawi and Botswana Country Overview and Data/Statistics, www.worldbank.org (accessed 07/08/2008).

WHO: 2006, World Health Organisation: World Health Statistics 2006, www.who.int (accessed 07/08/2008). 
Table 1. Organizations' CSR practices and relationship to identified stakeholder(s)

\begin{tabular}{|c|c|c|c|}
\hline \multirow[t]{2}{*}{ CSR Practices } & Identified Stakeholder(s) & \multicolumn{2}{|c|}{ Score } \\
\hline & & Mean & SD \\
\hline \multicolumn{4}{|l|}{ Practice $^{\mathrm{a}}$} \\
\hline $\begin{array}{l}\text { Provide all customers with the information needed to make sound } \\
\text { purchasing decisions }\end{array}$ & --- & 5.49 & 1.354 \\
\hline Satisfy the complaints of our customers about products or services & Customers & 5.33 & 1.339 \\
\hline Incorporate the interests of our customers in our business decisions & Customers & 5.36 & 1.425 \\
\hline Average & Customers & 5.34 & 1.267 \\
\hline $\begin{array}{l}\text { Treat suppliers, regardless of their size and location, fairly and } \\
\text { respectfully }\end{array}$ & Suppliers & 5.49 & 1.295 \\
\hline Incorporate the interests of our suppliers in our business decisions & Suppliers & 4.65 & 1.413 \\
\hline $\begin{array}{l}\text { Inform our suppliers about organizational changes affecting our } \\
\text { purchasing decisions }\end{array}$ & Suppliers & 4.24 & 1.556 \\
\hline Average & Suppliers & 4.84 & 1.147 \\
\hline Support our employees who want to pursue further education & --- & 5.11 & 1.669 \\
\hline $\begin{array}{l}\text { Provide procedures that help to insure the health and safety of our } \\
\text { employees }\end{array}$ & --- & 4.95 & 1.652 \\
\hline $\begin{array}{l}\text { Treat our employees fairly and respectfully, regardless of gender or } \\
\text { ethnic background }\end{array}$ & Employees & 5.55 & 1.408 \\
\hline Help our employees balance their private and professional lives & Employees & 4.36 & 1.543 \\
\hline Incorporate the interests of our employees in our business decisions & Employees & 4.53 & 1.526 \\
\hline $\begin{array}{l}\text { Provide our employees with salaries that properly and fairly reward them } \\
\text { for their work }\end{array}$ & Employees & 4.33 & 1.531 \\
\hline Average & \multirow{2}{*}{$\begin{array}{l}\text { Employees } \\
\text { Financial investors }\end{array}$} & 4.69 & 1.228 \\
\hline $\begin{array}{l}\text { Average } \\
\text { Provide our investors with full and accurate financial information about } \\
\text { the organization }\end{array}$ & & 5.60 & 1.417 \\
\hline Incorporate the interests of our investors in business decisions & Financial investors & 5.61 & 1.279 \\
\hline Inform our investors of changes in corporate policy & Financial investors & 5.55 & 1.266 \\
\hline Average & Financial investors & 5.64 & 1.131 \\
\hline $\begin{array}{l}\text { Incorporate the interests of the communities, where we operate, in our } \\
\text { business decisions }\end{array}$ & --- & 4.68 & 1.657 \\
\hline \multirow[b]{2}{*}{$\begin{array}{l}\text { Stimulate the economic development in the communities where we } \\
\text { operate. }\end{array}$} & \multirow{2}{*}{$\begin{array}{l}\text { Philanthropy } \\
\text { Philanthropy }\end{array}$} & 3.65 & 1.892 \\
\hline & & 4.12 & 1.828 \\
\hline Help improve the quality of life in the communities where we operate & Philanthropy & 4.33 & 1.812 \\
\hline Give money to charities in the communities where we operate & Philanthropy & 4.32 & 1.747 \\
\hline $\begin{array}{l}\text { Financially support activities (arts, culture, sports) in the communities } \\
\text { where we operate }\end{array}$ & Philanthropy & 4.15 & 1.872 \\
\hline Average & Philanthropy & 4.10 & 1.539 \\
\hline Voluntarily exceed government-imposed environmental regulations & Environment & 4.03 & 1.732 \\
\hline Incorporate environmental concerns in our business decisions & Environment & 4.54 & 1.661 \\
\hline $\begin{array}{l}\text { Incorporate environmental performance objectives in our organizational } \\
\text { plans }\end{array}$ & Environment & 4.43 & 1.620 \\
\hline Financially support environmental initiatives & Environment & 4.00 & 1.847 \\
\hline Measure our organization's environmental performance & Environment & 3.63 & 1.810 \\
\hline Minimize the environmental impact of all our organization's activities & Environment & 4.00 & 1.768 \\
\hline Average & Environment & 4.07 & 1.518 \\
\hline \multicolumn{4}{|l|}{ Organization's standing relative to that of competitors ${ }^{\mathrm{b}}$} \\
\hline \multicolumn{2}{|l|}{ Social policies and practices } & 3.36 & 1.028 \\
\hline \multicolumn{2}{|l|}{ Environmental policies and practices } & 3.02 & 1.084 \\
\hline \multicolumn{2}{|l|}{ Ethical policies and practices } & 3.67 & 1.072 \\
\hline \multicolumn{4}{|l|}{ Perceived effect of social, environmental, and ethical practices ${ }^{\mathrm{b}}$} \\
\hline \multicolumn{2}{|l|}{ Corporate image / reputation } & 3.65 & 1.126 \\
\hline \multicolumn{2}{|l|}{ Financial performance } & 3.23 & 1.169 \\
\hline \multicolumn{2}{|l|}{ Morale of its employees } & 3.18 & 1.124 \\
\hline \multicolumn{2}{|l|}{ Satisfaction of its customers } & 3.49 & 1.136 \\
\hline Satisfaction of other groups, for example employees, suppliers, and local & ommunity & 3.27 & 1.144 \\
\hline The wellbeing of people in general ('social welfare') & & 3.28 & 1.092 \\
\hline National and international visibility & & 3.41 & 1.175 \\
\hline Support from the government & & 3.26 & 1.341 \\
\hline
\end{tabular}

${ }^{\mathrm{a}}$ Scale used was $[\min 1 ; \max 7] ;{ }^{\mathrm{b}}$ Scale used was $[\min 1 ; \max 5]$. 
Table 2. Stakeholder influence

\begin{tabular}{llcc}
\hline Stakeholder $^{\mathbf{a}}$ & Relates to... & Mean & SD \\
\hline Employees & Workers & 3.10 & 1.107 \\
Middle-level managers & Workers & 3.41 & 1.077 \\
Average & Workers & 3.26 & 1.049 \\
Chief executive officer & Directors and owners & 4.23 & 1.034 \\
Board of directors & Directors and owners & 3.95 & 1.317 \\
Owners / shareholders & Directors and owners & $3 . .79$ & 1.369 \\
Average & Directors and owners & 4.01 & 1.101 \\
Customers & Market stakeholders & 3.00 & 1.222 \\
Suppliers & Market stakeholders & 2.57 & 1.046 \\
Competitors & Market stakeholders & 2.91 & 1.291 \\
Retailers & Market stakeholders & 2.36 & 1.117 \\
Trade unions & Market stakeholders & 2.29 & 1.250 \\
Average & Market stakeholders & 2.54 & 0.845 \\
Local communities & Other pressure groups & 2.68 & 1.274 \\
Press / media & Other pressure groups & 3.00 & 1.191 \\
Average & Other pressure groups & 2.83 & 1.066 \\
National regulators & Regulators & 3.75 & 1.119 \\
International regulators & Regulators & 3.21 & 1.420 \\
Average & Regulators & 3.47 & 1.125 \\
\hline
\end{tabular}

${ }^{\mathrm{a}}$ Scale used was [min $\left.1 ; \max 5\right]$.

Table 3. K-means two-clusters solution (solution from Ward's method)

\begin{tabular}{lcrrrrcc}
\hline Clusters & Variables & N & Minimum & Maximum & Mean & SD & Conclusion \\
\hline Organizations active in & CSR_Cust & 33 & 2.00 & 7.00 & 5.0606 & 1.36792 & High \\
the different CSR areas & CSR_Suppliers & & 2.00 & 7.00 & 4.7273 & 1.31881 & Medium \\
but slightly more & CSR_Empl & & 2.25 & 6.50 & 4.8282 & 1.21526 & Medium \\
focused on activities & CSR_Inv & & 1.00 & 7.00 & 4.9141 & 1.43016 & Medium \\
related to customers & CSR_Phil & & 1.80 & 6.80 & 4.8970 & 1.28561 & Medium \\
and the environment & CSR_Env & & 2.00 & 7.00 & 5.1313 & 1.15902 & High \\
Organizations focus on & CSR_Cust & 41 & 2.00 & 7.00 & 5.5610 & 1.19475 & High \\
CSR activities related & CSR_Suppliers & & 1.00 & 6.67 & 4.8171 & 1.13272 & Medium \\
to customers, investors & CSR_Empl & & 1.00 & 6.50 & 4.5141 & 1.24958 & Medium \\
(and also suppliers and & CSR_Inv & 2.00 & 7.00 & 5.9919 & 1.05538 & High \\
employees) & CSR_Phil & & 1.00 & 6.40 & 3.4049 & 1.40676 & Low \\
& CSR_Env & 1.00 & 5.17 & 3.2098 & 1.13101 & Low \\
\hline
\end{tabular}

Notes: The thresholds applied are as follows: Low < 4; Medium [4;5], and High > 5. 
Table 4. Differences across clusters (chi-square analyses)

\begin{tabular}{|c|c|c|c|c|}
\hline Variables & $\begin{array}{l}\text { Cluster } 1 \\
\mathrm{~N}(\% \text { within } \\
\text { the cluster) } \\
\end{array}$ & $\begin{array}{l}\text { Cluster } 2 \\
\mathrm{~N}(\% \text { within the } \\
\text { cluster) }\end{array}$ & Chi-square & p-values \\
\hline \multicolumn{5}{|l|}{ Organization age } \\
\hline Less than 10 years & $8(27.6 \%)$ & $10(33.3 \%)$ & 3.158 & 0.206 \\
\hline Between 11 and 30 years & $7(24.1 \%)$ & $12(40 \%)$ & & \\
\hline More than 30 years & $14(48.3 \%)$ & $8(26.7 \%)$ & & \\
\hline \multicolumn{5}{|l|}{ Organization size } \\
\hline Less than 20 employees & $3(9.4 \%)$ & $3(7.9 \%)$ & -- & -- \\
\hline Between 20 and 99 & $7(21.9 \%)$ & $24(63.2 \%)$ & & \\
\hline Between 100 and 999 & $15(46.9 \%)$ & $9(23.7 \%)$ & & \\
\hline 1000 or more & $7(21.9 \%)$ & $2(5.3 \%)$ & & \\
\hline \multicolumn{5}{|l|}{ CSR department? } \\
\hline A separate department & $11(34.4 \%)$ & $1(2.4 \%)$ & 14.573 & 0.001 \\
\hline Employees & $10(31.3 \%)$ & $13(31.7 \%)$ & & \\
\hline Neither & $11(34.4 \%)$ & $27(65.9 \%)$ & & \\
\hline \multicolumn{5}{|l|}{ Sales revenue in 2004} \\
\hline 10 million or less & $5(45.5 \%)$ & $21(67.7 \%)$ & -- & -- \\
\hline More than 10 million & $6(54.5 \%)$ & $10(32.3 \%)$ & & \\
\hline \multicolumn{5}{|c|}{ Business-to-business or business-to-consumer? } \\
\hline Business-to-business & $5(35.7 \%)$ & $5(26.3 \%)$ & --- & --- \\
\hline Business-to-consumers & $9(64.3 \%)$ & $14(73.7 \%)$ & & \\
\hline \multicolumn{5}{|l|}{ Goods or services? } \\
\hline Goods & $5(35.7 \%)$ & $0(0 \%)$ & -- & -- \\
\hline Services & $9(64.3 \%)$ & $19(100 \%)$ & & \\
\hline
\end{tabular}

-- The conditions to apply that test are not met because of a problem of sample size too low 
Table 5. Differences across clusters (ANOVA analyses)

\begin{tabular}{|c|c|c|c|c|}
\hline Variables & $\begin{array}{l}\text { Cluster } 1 \\
\text { Mean }\end{array}$ & $\begin{array}{l}\text { Cluster } 2 \\
\text { Mean }\end{array}$ & Fisher & p-values \\
\hline \multicolumn{5}{|l|}{ Stakeholders' influence } \\
\hline Employees & 3.28 & 2.93 & 1.993 & .162 \\
\hline Middle-level managers & 3.66 & 3.23 & 3.206 & .078 \\
\hline Chief executive officer & 4.09 & 4.43 & 2.334 & .131 \\
\hline Board of directors & 3.61 & 4.28 & 5.233 & .025 \\
\hline Owners / shareholders & 3.48 & 4.15 & 4.534 & .037 \\
\hline Customers & 3.09 & 3.00 & .113 & .738 \\
\hline Suppliers & 2.65 & 2.55 & .154 & .696 \\
\hline Competitors & 3.14 & 2.83 & 1.069 & .305 \\
\hline Retailers & 2.72 & 2.24 & 3.227 & .077 \\
\hline Trade unions & 2.58 & 2.03 & 3.910 & .052 \\
\hline Local communities & 3.13 & 2.28 & 9.022 & .004 \\
\hline Press / media & 3.16 & 2.93 & .708 & .403 \\
\hline National regulators & 3.66 & 3.87 & .746 & .391 \\
\hline International regulators & 3.19 & 3.33 & .158 & .692 \\
\hline \multicolumn{5}{|l|}{ Perceived CSR impact on... } \\
\hline $\begin{array}{l}\text { corporate image / } \\
\text { reputation }\end{array}$ & 4.06 & 3.35 & 7.813 & .007 \\
\hline financial performance & 3.55 & 2.95 & 5.053 & .028 \\
\hline employee morale & 3.09 & 3.28 & .502 & .481 \\
\hline customer satisfaction & 3.55 & 3.50 & .029 & .864 \\
\hline the satisfaction of other & 3.48 & 3.13 & & \\
\hline $\begin{array}{l}\text { groups, for example } \\
\text { employees, suppliers, } \\
\text { and local community }\end{array}$ & & & 1.876 & .175 \\
\hline $\begin{array}{l}\text { the wellbeing of people in } \\
\text { general ('social welfare') }\end{array}$ & 3.48 & 3.08 & 2.598 & .111 \\
\hline $\begin{array}{l}\text { national / international } \\
\text { visibility }\end{array}$ & 3.70 & 3.18 & 3.616 & .061 \\
\hline $\begin{array}{l}\text { support from the } \\
\text { government }\end{array}$ & 3.58 & 3.00 & 3.487 & .066 \\
\hline \multicolumn{5}{|l|}{$\begin{array}{l}\text { Performance relative to } \\
\text { expectations over } 2004 \\
\text { in terms of... }\end{array}$} \\
\hline customer relations & 3.46 & 3.72 & 1.470 & .230 \\
\hline employee relations & 3.32 & 3.11 & .678 & .413 \\
\hline environment relations & 3.39 & 2.86 & 3.890 & .053 \\
\hline $\begin{array}{l}\text { social health of the local } \\
\text { community }\end{array}$ & 3.11 & 2.53 & 5.970 & .017 \\
\hline $\begin{array}{l}\text { economic health of the } \\
\text { local community }\end{array}$ & 3.07 & 2.64 & 3.141 & .081 \\
\hline $\begin{array}{l}\text { relations with stakeholders } \\
\text { in general }\end{array}$ & 3.71 & 3.39 & 2.568 & .114 \\
\hline profitability & 3.74 & 3.49 & .664 & .419 \\
\hline $\begin{array}{l}\text { corporate image / } \\
\text { reputation }\end{array}$ & 3.79 & $2 . .86$ & .129 & .721 \\
\hline $\begin{array}{l}\text { national and international } \\
\text { visibility }\end{array}$ & 3.57 & 3.64 & .064 & .801 \\
\hline
\end{tabular}

